\title{
Knowing your neighbourhood - The effects of Epichloë endophytes on foliar fungal assemblages in perennial ryegrass in dependence of season and land-use intensity
}

\author{
Julia König $^{\text {Corresp., }}{ }^{1}$ ， Marco Alexandre Guerreiro ${ }^{2}$ ， Derek Peršoh ${ }^{2}$ ， Dominik Begerow ${ }^{2}$, Jochen Krauss ${ }^{1}$ \\ 1 Department of Animal Ecology and Tropical Biology, Biocentre, University of Würzburg, Würzburg, Germany \\ 2 Department of Geobotany, Ruhr-Universität Bochum, Bochum, Germany \\ Corresponding Author: Julia König \\ Email address: julia.koenig@uni-wuerzburg.de
}

Epichloë endophytes associated with cool season grass species can protect their hosts from herbivory and can suppress mycorrhizal colonization of the hosts' roots. However, little is known about whether or not Epichloë endophyte infection can also change the foliar fungal assemblages of the host. We tested 52 grassland study sites along a land-use intensity gradient in three study regions over two seasons (spring vs. summer) to determine whether Epichloë infection of the host grass Lolium perenne changes the fungal community structure in leaves. Foliar fungal communities were assessed by Next Generation Sequencing of the ITS rRNA gene region. Fungal community structure was strongly affected by study region and season in our study, while land-use intensity and infection with Epichloë endophytes had no significant effects. We conclude that effects on non-systemic endophytes resulting from land use practices and Epichloë infection reported in other studies were masked by local and seasonal variability in this study's grassland sites. 
1 Knowing your neighbourhood - The effects of Epichloë endophytes on foliar

2 fungal assemblages in perennial ryegrass in dependence of season and land-use

3

4 6 Krauss*

7

8

9 Hubland, Würzburg, Germany intensity Germany

Julia König*, Marco Alexandre Guerreiro†, Derek Peršoh†, Dominik Begerow $†$ and Jochen

*Department of Animal Ecology and Tropical Biology, University of Würzburg, Biocentre, Am $\dagger$ Department of Geobotany, Ruhr-University of Bochum, Universitätsstraße 150, Bochum,

13 Correspondence to: J. König, Department of Animal Ecology and Tropical Biology, University of 4 Würzburg, Biocentre, Am Hubland, Würzburg, Germany

5 E-mail: Julia.koenig@uni-wuerzburg.de 


\section{Abstract}

17 Epichloë endophytes associated with cool season grass species can protect their hosts from

18 herbivory and can suppress mycorrhizal colonization of the hosts' roots. However, little is known

19 about whether or not Epichloe endophyte infection can also change the foliar fungal assemblages

20 of the host. We tested 52 grassland study sites along a land-use intensity gradient in three study

21 regions over two seasons (spring vs. summer) to determine whether Epichloë infection of the host

22 grass Lolium perenne changes the fungal community structure in leaves. Foliar fungal

23 communities were assessed by Next Generation Sequencing of the ITS rRNA gene region. Fungal

24 community structure was strongly affected by study region and season in our study, while land-

25 use intensity and infection with Epichloë endophytes had no significant effects. We conclude that

26 effects on non-systemic endophytes resulting from land use practices and Epichloë infection

27 reported in other studies were masked by local and seasonal variability in this study's grassland 28 sites. 


\section{Introduction}

Fungi include ubiquitous and highly diverse microbial symbionts associated with a large number of plant species in all terrestrial ecosystems (Dix and Webster 1995). Such associations can have profound effects on ecosystems (van der Heijden et al. 1998; Clay and Holah 1999; Omacini et al. 2001; Bundrett 2006). Besides mycorrhizae, some of the best-known plant-fungus interactions are the symbioses of endophytes of the genus Epichlö (Ascomycota, Clavicipitaceae) with coolseason grass species in the family Poaceae (Schardl et al. 2004; Tanaka et al. 2012). Epichlö̈ endophytes systemically colonize above ground tissues of the host grass. Asexual Epichloë species are vertically transmitted through the seeds and provide several benefits to their hosts, like herbivore resistance and enhanced fitness (Schardl et al. 2004). Sexual species of Epichlö̈ endophytes produce spores which are transmitted horizontally by symbiotic flies of the genus Botanophila and supress the hosts' seed development (Schardl et al. 2004). Depending on abiotic and biotic conditions, the asexual Epichlö endophyte-grass association can shift from a mutualistic symbiosis to an antagonistic symbiosis, e.g. when herbivore pressure is low and nitrogen availability for the host is limited (Saikkonen et al. 1998; Müller and Krauss 2005). All grass species are associated with a large number of different fungal endophytes and often harbour more than one hundred species which colonize roots, stems and leaves of the plants (Sánchez Márquez et al. 2007). Therefore the systemic Epichloë endophytes represent only a small fraction of a diverse fungal community in grass species (Neubert et al. 2006). In contrast to Epichloë endophytes, most other endophytic fungi have a limited capacity to systemically colonize the plant organs or seeds (Rodriguez et al. 2009). In addition, the diverse endophytic fungi have unequal colonization frequencies with a few dominant genera, such as Alternaria, Acremonium, 
51 Cladosporium and Penicillium, which occur in multiple grass species, as well as in non-grass hosts

52 (Sánchez Márquez et al. 2012).

53 Diverse foliar fungal endophytes of plants are influenced by several abiotic and biotic factors 54 which may compromise the host species' ability to colonize, persist and disperse (Rodriguez et al. 55 2009). The fungal assemblages of grass leaves and frequencies of endophyte species change with 56 spatial distance and season (Sánchez Márquez et al. 2012). As these fungal species vary in their 57 dispersal ability, dissimilarities between fungal assemblages increase with distance (David et al. 58 2016). Depending on the prevailing microclimate, variability can be high at small spatial scales, 59 e.g. between individual leaves of a single tree, as well as between individual plants or different plant species (Stone et al. 2004; Rodriguez et al. 2009; Cordier et al. 2012; Scholtysik et al. 2013;

61 Peršoh 2015).

62 Several grass species, such as Lolium perenne, are of high agronomic importance and are part of 63 a regular food supply for livestock (Malinowski and Belesky 2006). Such grass species and their 64 interacting symbionts can be influenced by management of grasslands. For example, fertilization 65 and grazing can influence the availability of nutrients for host plants and vegetation structure 66 respectively, and have been shown to change individual fungal abundances, species richness and 67 the microbial community structure of fungal communities in soil (Donnison et al. 2000; Parrent et 68 al. 2006; Valyi et al. 2015; Soliveres et al. 2016). Thus, land-use intensity may also determine 69 foliar fungal assemblages of meadow or pasture grasses.

70 The interactions between species within fungal communities are little understood and may include 71 direct and/or indirect competition for plant resources (Saunders et al. 2010; Suryanarayanan 2013). 72 The systemic Epichloë endophytes produce chemical compounds which inhibit growth of 73 pathogenic fungi and generate shifts in below ground subsystems by suppressing the root 
74 colonization of mycorrhizal fungi (Siegel and Latch 1991; Yue et al. 2000; Clarke et al. 2006;

75 Mack and Rudgers 2008; Kumar and Kaushik 2012; Omacini et al. 2012; Vandegrift et al. 2015).

76 Thus, Epichloë endophytes may change the species composition of non-systemic fungal

77 endophytes in grass leaves as well. In this field study, we ask whether or not the presence of

78 systemic grass endophytes of the genus Epichloë changes the species composition of foliar fungal

79 assemblages in a host grass along a land-use intensity gradient in two seasons (spring and summer)

80 and in three geographic regions. 
81 Methods and Materials

82 Study sites

83 The study was conducted on 150 grassland sites within the framework of the Biodiversity

84 Exploratories (www.biodiversity-exploratories.de), which includes three distinct regions across

85 Germany. The three study regions; Schwäbische Alb (south-west Germany, ALB), Hainich-Dün

86 (central Germany, HAI) and Schorfheide-Chorin (north-east Germany, SCH), represent different

87 climatic conditions, soil types, landscapes and land-use types, as well as different management

88 intensities (Fischer et al. 2010). All selected study sites are real-world grasslands and are not experimental plots (Fischer et al. 2010). Rather, they are grasslands used by the owners or farmers to meet their needs without artificial changes by researchers (Fischer et al. 2010). Some owners' management strategies have included sowing grasslands with commercial seed mixtures within the last ten years. Such real-world study systems are necessary to show how ecosystems work, but bear the risk of lower replicability compared to controlled laboratory experiments. The grasslands are classified along a land-use intensity gradient (LUI), which integrates the most common practices such as mowing, grazing, and fertilization, into one index, comprising values from zero (extensive) to four (intensive; Bluethgen et al. 2012). Intensively managed grasslands are fertilized, grazed by livestock several times during the year and/or mown repeatedly. Extensively managed grasslands, such as semi-natural grasslands, including protected calcareous grasslands and wetlands, are not fertilized and are mown only once and/or grazed for only a short time

100 (Bluethgen et al. 2012). For this study we used the LUI calculated for the management in 2014, 101 one year before our sampling in 2015.

102 Field work permits were issued by the responsible state environmental offices of Baden103 Württemberg, Thüringen, and Brandenburg (according to $§ 72$ BbgNatSchG). 


\section{Plant sampling}

106

107

108

109

110

111

112

113

114

115

116

117

The perennial ryegrass Lolium perenne was selected as the study species, as it is an important forage grass which is commonly associated with the vertically transmitted endophyte Epichlö̈ festucae var. lolii (formerly Neotyphodium lolii; Klapp et al. 2013; Leuchtmann et al. 2014). Samples of L. perenne were collected in all three study regions in spring and summer surveys in 2015. In total, 80 sites within the 150 grasslands contained L. perenne populations and were sampled. In each survey, we sampled up to 20 L. perenne plants randomly at different locations at each study site, with a minimum distance of $1 \mathrm{~m}$ between sampled plants to reduce the probability of sampling the same plant twice. The number of sampled plants per study site differed depending on the population size of L. perenne and on recent mowing and/or grazing events. Overall, 2147 plants were sampled. Approximately $3 \mathrm{~cm}$ of one grass tiller from each plant was collected, and included basal stem, leaf sheaths, and basal leaf blades (König et al. in press). The mycelia of Epichloë endophytes accumulate mainly in basal leaf sheaths of the grasses (Spiering et al. 2005).

The collected basal stem and leaf sheaths of the tillers were therefore used to detect Epichlö infections using immunoblot assays (Figure 1a). As leaf blades contain a high diversity of fungal endophytes (Sánchez Márquez et al. 2007; Sánchez Márquez et al. 2008; Sánchez Márquez et al. 2010), foliar fungal assemblages of one Epichlö̈-infected and one Epichlö̈-free grass individual per study site and season were assessed in the basal leaf blades (Figure 1b). The sampled plant material was stored separately for each individual in $2.5 \mathrm{ml}$ Eppendorf reaction tubes. During the field survey, all samples were immediately cooled with dry ice. To prevent degradation of the fungal DNA, plant samples were stored afterwards at $-20^{\circ} \mathrm{C}$ (Peay et al. 2013; Millberg et al. 2015). 


\section{Epichloë endophyte detection}

128 To detect Epichloë endophytes in the basal stem and leaf sheaths, a commercially available kit for

129 immunoblot assays was used, following the manufacturer's protocol (www.agrinostics.com). In

130 total, 270 (12.6\%) of 2147 sampled L. perenne plants were infected with an Epichloë endophyte.

131 To compare fungal assemblages of Epichlö̈-infected and Epichlö̈-free samples, 52 sites with

132 Lolium perenne which contained both infected and un-infected individuals were chosen from the

13380 grassland sites. Depending on recent mowing or grazing events, 21 of the 52 grasslands were

134 sampled exclusively in spring and 15 grasslands exclusively in summer, while 16 grasslands could

135 be sampled in both seasons. As $43 \%$ of grasslands contained less than three Epichloë-infected

136 plant individuals, one immuno-positive (Epichlö̈-infected, E+) and one immuno-negative

137 (Epichlö̈-free, E-) plant sample for each grassland site and season was randomly selected, 138 resulting in a total of $68 \mathrm{E}+$ and $68 \mathrm{E}$ - samples.

\section{Foliar fungal assemblages}

141 For analyses of the foliar fungal assemblages by Next Generation Sequencing (NGS), 68 E+ and

14268 E- leaf blades were used. In order to detect the complete foliar (i.e. epi- and endophytic) fungal 143 assemblage on the grass leaves the leaf blades were not surface sterilized.

\section{DNA extraction}

146 The ChargeSwitch ${ }^{\circledR}$ gDNA Plant Kit (Invitrogen ${ }^{\mathrm{TM}}$ ) was used to extract DNA as recommended 147 by the manufacturer, but with volumes scaled down to $10 \%$. Cell disruption was achieved using 148 a FastPrep ${ }^{\circledR}-24$ Instrument (MP Biomedicals) as detailed by Guerreiro et al. (in press). 


\section{Library preparation and sequencing}

151 The fungal barcoding region, i.e., the ITS rRNA gene region, was amplified as detailed by

152 Guerreiro et al. (in press). Briefly, library preparation comprised two sequential amplification

153 steps. In the first PCR, the fungus specific primers ITS1F and ITS4 were used and modified at the

1545 '-ends to include sample-specific TAG sequences. In the second PCR, the sequencing primers,

155 indices, and the P5 and P7 adapters for the Illumina sequencing were appended. Libraries were

156 processed by the sequencing service of the Faculty of Biology at LMU Munich, and sequenced

157 using an Illumina MiSeq ${ }^{\circledR}$ sequencer (Illumina, Inc., San Diego, CA, USA) with $2 \times 250$ bp paired

158 end sequencing (MiSeq Reagent Kit v3 Chemistry, Illumina, Inc., San Diego, CA, USA).

\section{Processing of sequencing data}

161 The obtained sequence reads were processed as detailed by Guerreiro et al. (in press). Briefly, the 162 sequences were demultiplexed using QIIME version 1.9.0 (Caporaso et al. 2010). Using the FastX 163 toolkit (http:/hannonlab.cshl.edu/fastx toolkit), reads were trimmed at the 5 '-end to comprise only

164 the final $11 \mathrm{bp}$ of the SSU rRNA gene region. These pre-processed sequence data were deposited 165 in the European Nucleotide Archive database (http://www.ebi.ac.uk/ena/data/view/PRJEB23523). CD-HIT-OTU for Illumina reads. Version 0.0.1 (http://weizhongli-lab.org/cd-hit-otu, Li et al. 2012) was selected for clustering reads into Operational Taxonomic Units (OTUs) at a similarity threshold of $97 \%$, according to a previous comparison of the performance of clustering algorithms (Röhl et al. 2017). A matrix (OTU table) listing the read count per OTU and sample was generated, which was used for statistical analyses and was deposited in BExIS database (ID 22188). The

171 taxonomic affiliation of each OTU was assigned using the UNITE database version 7.1 (Kõljalg 172 et al. 2005) as reference. 
173 Samples with less than 15,000 reads were discarded and the OTU read counts were standardized

174 per sample by the total number of reads. Sequence processing revealed 247 fungal OTUs,

175 represented by 4,907,006 quality-filtered ITS1 sequence reads. As eight samples had to be

176 discarded after the ITS sequencing, we ended up with a sample size of 128 (63 E+ and 65 E-) from

177 (a) 19 sites in the region ALB, together 46 samples (spring 24, summer 22); (b) 14 sites in the

178 region HAI, together 30 samples (spring 22, summer 8); and (c) 19 sites in the region $\mathrm{SCH}$, 179 together 52 samples (spring 23, summer 29).

\section{Statistical analyses}

For statistical analyses, the software R version 3.1.1 (R Development Core Team, 2014) was used.

The effects of the following explanatory variables were tested using linear mixed effect models

region, (iv) land-use intensity on the response variables "species richness" (number of OTUs), "species evenness" and "Shannon diversity" of the OTUs. Study site ID was included as random intercept. Unequal sample sizes for region and season lead to an unbalanced sampling design, but E+ and E- samples were almost equal (one E+, one E-) for each studied grassland. To compare species richness, species evenness, and Shannon diversity between season and region, Tukey's HSD comparison of groups in mixed effects models was used (GLHT, multcomp package, Hothorn et al. 2008). Differences between the composition of foliar fungal assemblages in dependence of region, season, land-use intensity and Epichloë endophyte infection were tested with a PERMANOVA (9999 permutations) (ADONIS, package vegan, Oksanen et al. 2017). It fits a linear model to a distance matrix and tests hypotheses by permutations, thus not assuming normality of the data (Anderson 2001). To characterize compositional differences between foliar 
196 fungal assemblages, non-metric multidimensional scaling (NMDS, vegan package, Oksanen et al.

197 2017) based on Bray-Curtis dissimilarities was used. Mean \pm SE are used throughout the 198 manuscript unless otherwise specified.

199 
200

201

202

203

204

205

206

207

208

209

210

211

212

213

214

215

216

217 The foliar fungal assemblages of L. perenne were significantly different among the regions (Table 218

219

220

221

\section{Results}

We identified 247 fungal OTUs associated with 128 L. perenne leaves (63 E+, 65 E-) and identified 33 genera. In total, $59 \%$ of the OTUs were assigned to Ascomycota, $33 \%$ to Basidiomycota and less than $1 \%$ to Chytridiomycota (Table 1 ). Approximately $8 \%$ of the OTUs could be not identified at the phylum level (Table 1), which is below the proportion of unassignable fungi in NGS surveys of different habitats such as tree leaves (40\%, Yang et al. 2016), submerged litter (36 \%, Röhl et al. 2017), or dead wood (16 \%, Peršoh and Borken 2017). The orders contributing the most species to the foliar fungal assemblages of $L$. perenne were the Pleosporales $(15 \%$ of OTUs), Heliotiales ( $8 \%$ of OTUs) and Hypocreales (5 \% of OTUs; Table 1 ). The dominant genera contributing to the foliar fungal assemblages of $L$. perenne were Cryptococcus ( $25 \%$ of the sequencing reads), a genus of Basidiomycota, and Mycosphaerella (11\% of the sequencing reads; Table 2), a genus of Ascomycota.

The sample sizes of analysed L. perenne plants differed slightly between the studied regions (ALB $=46, \mathrm{HAI}=30, \mathrm{SCH}=52)$ and between seasons $($ spring $=69$, summer $=59)$. Nonetheless, separate species (OTU) accumulation curves for the studied regions (ALB $=216$ OTUs, HAI = 205 OTUs, $\mathrm{SCH}=220$ OTUs) and seasons (spring = 233 OTUs, summer $=215$ OTUs; Figure 2a, b) were close to saturation. 3), with lowest species richness and highest species evenness in the southernmost and coolest region, $\mathrm{ALB}$ (number of OTUs $=51 \pm 3$, evenness $=0.23 \pm 0.004$ ), compared to HAI (number of OTUs $=63 \pm 3$, evenness $=0.20 \pm 0.003)$ and SCH (number of OTUs $=62 \pm 3$, evenness $=0.21 \pm$ $0.004)$, but with no differences in Shannon diversity $(\mathrm{ALB}=2.55 \pm 0.10, \mathrm{HAI}=2.52 \pm 0.10, \mathrm{SCH}$ 
$222=2.63 \pm 0.10 ;$ Figure 3). The assemblages in ALB and SCH were distributed in a loosely scattered

223 pattern, while fungal assemblages in the HAI region were more similar to one another (Figure 4a).

224 Season significantly affected species richness and composition of the assemblages (Table 3).

225 Species richness and Shannon diversity were higher and compositions of the foliar fungal

226 assemblages were more similar in summer (number of OTUs $=69 \pm 3$, Shannon $=2.66 \pm 0.10$ )

227 compared to spring (number of OTUs $=49 \pm 2$, Shannon $=2.50 \pm 0.10$ ). Species evenness,

228 however, peaked in spring (spring: evenness $=0.23 \pm 0.004$, summer: evenness $=0.21 \pm 0.003$;

229 Figure 3; 4b).

230 Neither land-use intensity nor infection with Epichloë endophytes had a significant effect on

231 species richness (number of OTUs: $\mathrm{E}+=56 \pm 3, \mathrm{E}-=60 \pm 3$ ) or composition of fungal assemblages

232 of L. perenne leaves (Table 3, Figures 4c, d).

233 From all 63 immunoblot positive $(\mathrm{E}+)$ samples of basal stems and leaf sheaths, only $17 \%(11$

234 samples) indicated the occurrence of Epichloë festucae var. lolii in lower leaf blades using the

235 NGS method. In $5 \%$ (7 of all 128 analysed L. perenne samples), NGS detected Epichloë 236 uncinata. 


\section{Discussion}

238 Many of the dominant and ubiquitous ascomycetes detected by NGS in our study, including several

239 taxa such as Acremonium, Alternaria, Cladosporium, Epicoccum and Penicillium, have previously

240 been recorded in other grass species (Sánchez Márquez et al. 2007; Sánchez Márquez et al. 2010)

241 and in L. perenne (Thomas and Shattock 1986) with direct isolation methods. In contrast to these

242 studies, the fungal genus that dominated in our study belonged to the Basidiomycota

243 (Cryptococcus). With direct isolation methods, only cultivable fungi can be detected, while

244 indirect methods such as NGS can also detect fungi which cannot be cultured in vitro. Such

245 differences in detection probabilities may have resulted the observed differences between our

246 study and those of others. However, the presence of numerous fungal species seems to be

247 characteristic of the mycobiome of grasses, leading to large compositional similarities in

248 comparisons of fungal assemblages from different grass species (Neubert et al. 2006; Sánchez

249 Márquez et al. 2007; White and Backhouse 2007; Sánchez Márquez et al. 2008; Sánchez Márquez

250 et al. 2010).

251

252

\section{Effects of region, season and land-use intensity}

253 The three study regions; ALB, HAI, and $\mathrm{SCH}$, span a latitudinal gradient from south to north 254 across Germany, including different grassland types with variable vegetation structures (Fischer 255 et al. 2010). The total number of OTUs was similar between regions, but the fungal assemblages, 256 including mean number of OTUs, differed strongly between the regions in our study. Similarly, 257 other studies have also found differences between regions for fungal assemblages of other grass 258 species (Wirsel et al. 2001; Wilberforce et al. 2003; Neubert et al. 2006; Sánchez Márquez et al. 259 2008). The environmental context of study sites, including soil, vegetation, surrounding landscape, 
260 weather, and climate may contribute to differences in the foliar fungal assemblages among the

261 three regions in our study.

262 Apart from study region, species richness and species composition changed between spring and 263 summer. Similar seasonal changes have been observed in fungal assemblages of different tree 264 species (Peršoh 2015). This seasonal pattern may be due to the accumulation of aerial and rain-

265 dispersed fungal spores over time (Sánchez Márquez et al. 2012). As leaves grow older, 266 susceptibility to infections by horizontally transmitted fungal endophytes increases (Balazs et al. 267 1973; Iwasa et al. 1996); and leaves of temperate grasses tend to die with summer drought 268 (Sánchez Márquez et al. 2012). This could explain the significantly higher species richness and 269 Shannon diversity but lower species evenness in summer as compared to spring.

270 In contrast to region and season, land-use intensity had a minor impact on foliar fungal 271 assemblages of L. perenne in our study. A recent study found that taxonomic richness of different 272 endophytic fungi, including mycorrhizal fungi in roots, decreased with increasing mowing 273 intensity on the same study sites in the three regions (Simons et al. 2017). Another study found 274 that both, species richness and diversity, of below ground fungi were negatively affected by 275 increased $\mathrm{N}$ mineralization rates, but effects on abundances of different taxa varied (Parrent et al. 276 2006). We assume that different management practices, such as mowing or fertilization, essentially 277 change the likelihood of the occurrence of any single species, but that the overall effect on fungal 278 assemblages remains rather low.

\section{Effects of Epichlö̈ endophytes}

While infections with Epichloë endophytes has been shown to affect mycorrhizal colonization of grasses (Mack and Rudgers 2008; Omacini et al. 2012; Vandegrift et al. 2015), it had no significant 
283 effect on the foliar fungal assemblages of $L$. perenne in our study. Similar to a recent study on

284 Festuca rubra and Epichloë festucae (Zabalgogeazcoa et al. 2013), neither species richness nor

285 the composition of fungal communities in leaves changed between Epichloë-infected and

286 Epichlö̈-free samples. We analysed fungi from the surfaces and internal tissues of L. perenne

287 leaves. In addition to endophytic species, fungal epiphytes and spores on the outer surface of the

288 grass leaves were detected in our study. The presence of these epiphytes and spores may have

289 confounded our results somewhat, as we assume that Epichlö̈ endophytes have a stronger effect

290 on fungi which had invaded the leaves

291 Interestingly, in only $17 \%$ of the plants where an infection with E. festucae var. lolii was detected

292 in the basal stems and leaf sheaths by immunoblot assays $(\mathrm{E}+)$, the endophyte species was also

293 detected by NGS in the lower leaf blades. Infection rates of Epichloë may differ among plant parts

294 (Spiering et al. 2005) and the limited specificity of immunoblot assays may result in false positive

295 results (Jensen et al. 2011). Epichloë fungal DNA in the host plants increase with plant age (Fuchs

296 et al. 2017) and therefore, younger basal stems have a lower detection probability of the fungi

297 compared to older plants. The reason why we achieved such low overlap between the two methods

298 needs further study, as a causal connection could not be established with our study design and

299 sampling methods, using different plant material for the immunoblot assays and NGS.

300 Furthermore, in some L. perenne plants (5\%), independent of the Epichloë infection detected by

301 immunoblot assays, NGS detected Epichloë uncinata, a species not found in L. perenne

302 (Leuchtmann et al. 2014). Since we sampled L. perenne plants at the vegetative stage in 303 heterogeneous and species rich grasslands, we may have sometimes inadvertently sampled the 304 hybrid Festulolium or young meadow fescue tillers (Festuca pratensis). Festulolium can be 305 visually difficult to distinguish from L. perenne and farmers have seeded this hybrid; it is 
306 frequently included in seed mixtures used by managers (personal communication with grassland

307 farmers and owners). Both Festulolium and F. pratensis species can serve as hosts of E. uncinata.

308 Epichloë uncinata itself is a hybrid of the species Epichloë bromicola and the E. typhina complex,

309 and E. typhina has been recorded in L. perenne (Leuchtmann et al. 2014). This may explain, at

310 least in part, the detection of E. uncinata in our samples.

\section{Conclusion}

313 Our results demonstrated that, in all regions, the leaves of the grass L. perenne contain more than

314200 taxa of fungal endo- and/or epiphytes. The number of OTUs ranges from 50-70 fungal taxa

315 per study site depending on region and season. We therefore conclude that the fungal community

316 composition of the leaves depends on study region and season, while land-use intensity of the

317 grasslands and the occurrence of Epichloë endophytes in the grass has a minor influence on the

318 foliar endo- and epiphytes in our study. However, land-use intensity has been shown to drive

319 communities of endophytes (Parrent et al. 2006; Valyi et al. 2015; Soliveres et al. 2016; Simons

320 et al. 2017) and the occurrence of Epichloë endophytes changes the expression of over one third

321 of the host genes (Dupont et al. 2015) and can also increase resistance to pathogenic fungi (Bonos

322 et al. 2005; Clarke et al. 2006; Vignale et al. 2013; Xia et al. 2015). Further studies are needed to

323 exclude the epiphytes and spores on the leaves (e.g. by surface sterilisation), and to detect effects

324 of land use and Epichloë endophytes on the fungal diversity of host plants, with a focus on specific

325 and perhaps competing groups of endophytic fungi in the host. 


\section{Acknowledgements}

327 We thank the editor Teri Balser, Maria Julissa Ek Ramos and one anonymous reviewer for helpful

328 comments on our manuscript, Kathleen Regan for a profound native speaker check and Lena Papp

329 and Christopher Sadlowski for assisting in lab work. Andreas Brachmann (Munich) supported

330 library preparation and conducted the Illumina sequencing. We thank the managers of the three

331 Exploratories, Kirsten Reichel-Jung, Katrin Lorenzen, Martin Gorke and all former managers for

332 their work in maintaining the plot and project infrastructure, with special thanks to Uta

333 Schumacher, Steffen Both and Ralf Lauterbach for supporting field work and communication with

334 local farmers. We also thank Christiane Fischer, Jule Mangels, Anja Höck and Cornelia Weist for 335 giving support through the central office, Michael Owonibi for managing the central data base, 336 and Markus Fischer, Eduard Linsenmair, Dominik Hessenmöller, Daniel Prati, Ingo Schöning, 337 François Buscot, Ernst-Detlef Schulze, Wolfgang W. Weisser and the late Elisabeth Kalko for 338 their role in setting up the Biodiversity Exploratories project. 
339 References

340 Anderson MJ, 2001. A new method for non-parametric multivariate analysis of variance. Austral

341 Ecology 26: 32-46.

342 Balazs E, Gaborjanyi R and Kiraly Z, 1973. Leaf senescence and increased virus susceptibility in 343 tobacco - Effect of abscisic-acid. Physiological Plant Pathology 3: 341-346.

344 Bluethgen N, Dormann CF, Prati D, Klaus VH, Kleinebecker T, Hoelzel N, Alt F, Boch S, Gockel

345 S, Hemp A, Mueller J, Nieschulze J, Renner SC, Schoening I, Schumacher U, Socher SA, Wells

346 K, Birkhofer K, Buscot F, Oelmann Y, Rothenwoehrer C, Scherber C, Tscharntke T, Weiner CN,

347 Fischer M, Kalko EKV, Linsenmair KE, Schulze E-D and Weisser WW, 2012. A quantitative

348 index of land-use intensity in grasslands: Integrating mowing, grazing and fertilization. Basic and 349 Applied Ecology 13: 207-220.

350 Bonos SA, Wilson MM, Meyer WA and Funk CR, 2005. Suppression of red thread in fine fescues 351 through endophyte-mediated resistance. Applied Turfgrass Science 10: 1094.

352 Bundrett MC, 2006. Understanding the roles of multifunctional mycorrhizal and endophytic fungi.

353 In: Schulz BJE, Boyle CJC, Sieber TN (Eds.), Microbial Root Endophytes. Springer-Verlag Berlin 354 Heidelberg, Germany, pp. 281-298.

355 Caporaso JG, Kuczynski J, Stombaugh J, Bittinger K, Bushman FD, Costello EK, Fierer N, Pe na 356 AG, Goodrich JK, Gordon JI, Huttley GA, Kelley ST, Knights D, Koenig JE, Ley RE, Lozupone 357 CA, McDonald D, Muegge BD, Pirrung M, Reeder J, Sevinsky JR, Turnbaugh PJ, Walters WA, 358 Widmann J, Yatsunenko T, Zaneveld J and Knight R, 2010, 2010. QIIME allows analysis of 359 highthroughput community sequencing data. Nature Methods 7: 335-336.

360 Clarke BB, White JF, Hurley RH, Torres MS, Sun S and Huff DR, 2006. Endophyte-mediated 361 surppression of dollar spot disease in fine fescues. Plant Disease 90: 994-998. 
362 Clay K and Holah J, 1999. Fungal endophyte symbiosis and plant diversity in successional fields.

363 Science 285: 1742-1744.

364 Cordier T, Robin C, Capdevielle X, Desprez-Loustau ML and Vacher C, 2012. Spatial variability 365 of phyllosphere fungal assemblages: Genetic distance predominates over geographic distance in a 366 European beech stand (Fagus syluatica). Fungal Ecology 5: 509-520.

367 David AS, Seabloom EW and May G, 2016. Plant host species and geographic distance affect the 368 structure of aboveground fungal symbiont communities, and environmental filtering affects 369 belowground communities in a coastal dune ecosystem. Microbial Ecology 71: 912-926.

370 Dix NJ and Webster J, 1995. Fungal Ecology. Springer Netherlands, Dordrecht.

371 Donnison LM, Griffith GS, Hedger J, Hobbs PJ and Bardgett RD, 2000. Management influences 372 on soil microbial communities and their function in botanically diverse haymeadows of northern 373 England and Wales. Soil Biology \& Biochemistry 32: 253-263.

374 Dupont P-Y, Eaton CJ, Wargent JJ, Fechtner S, Solomon P, Schmid J, Day RC, Scott B and Cox 375 MP, 2015. Fungal endophyte infection of ryegrass reprograms host metabolism and alters 376 development. New Phytologist 208: 1227-1240.

377 Fischer M, Bossdorf O, Gockel S, Hansel F, Hemp A, Hessenmoller D, Korte G, Nieschulze J, 378 Pfeiffer S, Prati D, Renner S, Schoning I, Schumacher U, Wells K, Buscot F, Kalko EKV, 379 Linsenmair KE, Schulze E-D and Weisser WW, 2010. Implementing large-scale and long-term 380 functional biodiversity research: The Biodiversity Exploratories. Basic and Applied Ecology 11: $381 \quad 473-485$.

382 Fuchs B, Krischke M, Mueller MJ and Krauss J (2017) Plant age and seasonal timing determine 383 endophyte growth and alkaloid biosynthesis. Fungal Ecology, 29: 52-58. 
384 Guerreiro M, Brachmann A, Begerow D and Peršoh D, in press. Transient leaf endophytes are the 385 most active fungi in 1-year-old beech leaf litter. Fungal Diversity, DOI 10.1007/s13225-017-03903864.

387 Hothorn T, Bretz F and Westfall P, 2008. Simultaneous inference in general parametric models. 388 Biometrical Journal 50: 346-363.

Iwasa Y, Kubo T, VanDam N and DeJong TJ, 1996. Optimal level of chemical defense decreasing with leaf age. Theoretical Population Biology 50: 124-148.

Jensen JB, Gonzalez VT, Guevara DU, Bhuvaneswari TV, Wali PR, Tejesvi MV, Pirttila AM, Bazely D, Vicari M and Brathen KA, 2011. Kit for detection of fungal endophytes of grasses yields inconsistent results. Methods in Ecology and Evolution 2: 197-201.

Klapp E and Opitz von Boberfeld W, 2013. Taschenbuch der Gräser. Eugen Ulmer KG, Stuttgart, D.

Kõljalg U, Larsson K-H, Abarenkov K, Nilsson RH, Alexander IJ, Eberhardt U, Erland S, Høiland K, Kjøller R, Larsson E, Pennanen T, Sen R, Taylor AFS, Tedersoo L, Vrålstad T and Ursing BM, 2005. UNITE: A database providing webbased methods for the molecular identification of ectomycorrhizal fungi. The New Phytologist 166: 1063-1068.

König J, Fuchs B, Krischke M, Mueller MJ and Krauss J, in press. Hide and seek - Infection rates and alkaloids concentrations of Epichloë festucae var. lolii in Lolium perenne along a land-use gradient in Germany. Grass and Forage Science, DOI 10.111/gfs.12330.

Kumar S and Kaushik N, 2012. Metabolites of endophytic fungi as novel source of biofungicide: A review. Phytochemical Reviews 11: 507-522.

Leuchtmann A, Bacon CW, Schardl CL, White JF, Jr. and Tadych M, 2014. Nomenclatural realignment of Neotyphodium species with genus Epichlö̈. Mycologia, 106: 202-215. 
407 Li W, Fu L, Niu B, Wu S and Woodley J, 2012. Ultrafastclustering algorithms for metagenomics 408 sequence analysis. Briefings in Bioinformatics 13: 656-668.

409 Mack KML and Rudgers JA, 2008. Balancing multiple mutualists: Asymmetric interactions 410 among plants, arbuscular mycorrhizal fungi, and fungal endophytes. Oikos 117: 310-320.

411 Malinowski DP and Belesky DP, 2006. Ecological importance of Neotyphodium spp. grass 412 endophytes in agroecosystems. Grassland Science 52: 1-14.

413 Millberg H, Boberg J and Stenlid J, 2015. Changes in fungal community of scots pine (Pinus 414 sylvestris) needles along a latitudinal gradient in Sweden. Fungal Ecology 17: 126-139.

415 Müller CB and Krauss J, 2005. Symbiosis between grasses and asexual fungal endophytes. Current 416 Opinion in Plant Biology 8: 450-456.

417 Neubert K, Mendgen K, Brinkmann H and Wirsel SGR, 2006. Only a few fungal species dominate 418 highly diverse mycofloras associated with the common reed. Applied and Environmental 419 Microbiology 72: 1118-1128.

420 Oksanen J, Guillaume Blanche F, Friendly M, Kindt R, Legendre P, McGlinn D, Minchin PR,

421 O'Hara RB, Simpson GL, Solymos P, Henry M, Stevens H, Szoecs E and Wagner H, 2017.

422 Community Ecology Package. https://cran.r-project.org

423 Omacini M, Chaneton EJ, Ghersa CM and Muller CB, 2001. Symbiotic fungal endophytes control 424 insect host-parasite interaction webs. Nature 409: 78-81.

425 Omacini M, Semmartin M, Perez LI and Gundel PE, 2012. Grass-endophyte symbiosis: A 426 neglected aboveground interaction with multiple belowground consequences. Applied Soil 427 Ecology 61: 273-279.

428 Parrent JL, Morris WF and Vilgalys R, 2006. CO2-enrichment and nutrient availability alter 429 ectomycorrhizal fungal communities. Ecology 87: 2278-2287. 
430 Peay KG, Baraloto C and Fine PVA, 2013. Strong coupling of plant and fungal community

431 structure across western Amazonian rainforests. The ISME Journal 7: 1852-1861.

432 Peršoh D, 2015. Plant-associated fungal communities in the light of meta'omics. Fungal Diversity 433 75: 1-25.

434 Peršoh D and Borken W, 2017. Impact of woody debris of different tree species on the microbial 435 activity and community of an underlying organic horizon. Soil Biology \& Biochemistry 115: 516$436 \quad 525$.

437 Pinheiro JD, Bates D, DebRoy S, Sarkar D and Team tRC, 2016. Nlme: Linear and nonlinear 438 mixed effects models (R package version 3.1-128). http://CRAN.R-project.org/package=nlme

439 Rodriguez RJ, White JF, Jr., Arnold AE and Redman RS, 2009. Fungal endophytes: Diversity and 440 functional roles. New Phytologist 182: 314-330.

441 Röhl O, Peršoh D, Mittelbach M, Elbrecht V, Brachmann A, Nuy J, Boenigk J, Leese F and 442 Begerow D, 2017. Distinct sensitivity of fungal freshwater guilds to water quality. Mycological 443 Progress 16: 155-169.

444 Saikkonen K, Faeth SH, Helander M and Sullivan TJ, 1998. Fungal endophytes: A continuum of 445 interactions with host plants. Annual Review of Ecology and Systematics 29: 319-343.

446 Sánchez Márquez SS, Bills GF, Acuna LD and Zabalgogeazcoa I, 2010. Endophytic mycobiota of 447 leaves and roots of the grass Holcus lanatus. Fungal Diversity 41: 115-123.

448 Sánchez Márquez SS, Bills GF, Herrero N and Zabalgogeazcoa I, 2012. Non-systemic fungal 449 endophytes of grasses. Fungal Ecology 5: 289-297.

450 Sánchez Márquez SS, Bills GF and Zabalgogeazcoa I, 2007. The endophytic mycobiota of the 451 grass Dactylis glomerata. Fungal Diversity 27: 171-195. 
452 Sánchez Márquez SS, Bills GF and Zabalgogeazcoa I, 2008. Diversity and structure of the fungal

453 endophytic assemblages from two sympatric coastal grasses. Fungal Diversity 33: 87-100.

454 Saunders M, Glenn AE and Kohn LM, 2010. Exploring the evolutionary ecology of fungal

455 endophytes in agricultural systems: Using functional traits to reveal mechanisms in community

456 processes. Evolutionary Applications 3: 525-537.

457 Schardl CL, Leuchtmann A and Spiering MJ, 2004. Symbioses of grasses with seedborne fungal 458 endophytes. Annual Review of Plant Biology 55: 315-340.

459 Scholtysik A, Unterseher M, Otto P and Wirth C, 2013. Spatio-temporal dynamics of endophyte 460 diversity in the canopy of European ash (Fraxinus excelsior). Mycological Progress 12: 291-304.

461 Siegel MR and Latch GCM, 1991. Expression of antifungal activity in agar culture by isolates of 462 grass endophytes. Mycologia 83: 529-537.

463 Simons NK, Lewinsohn T, Bluthgen N, Buscot F, Boch S, Daniel R, Gossner MM, Jung K, Kaiser 464 K, Muller J, Prati D, Renner SC, Socher SA, Sonnemann I, Weiner CN, Werner M, Wubet T, 465 Wurst S and Weisser WW, 2017. Contrasting effects of grassland management modes on species466 abundance distributions of multiple groups. Agriculture Ecosystems \& Environment 237: 143-153. 467 Soliveres S, Manning P, Prati D, Gossner MM, Alt F, Arndt H, Baumgartner V, Binkenstein J, 468 Birkhofer K, Blaser S, Bluthgen N, Boch S, Bohm S, Borschig C, Buscot F, Diekotter T, Heinze 469 J, Holzel N, Jung K, Klaus VH, Klein AM, Kleinebecker T, Klemmer S, Krauss J, Lange M, 470 Morris EK, Muller J, Oelmann Y, Overmann J, Pasalic E, Renner SC, Rillig MC, Schaefer HM, 471 Schloter M, Schmitt B, Schoning I, Schrumpf M, Sikorski J, Socher SA, Solly EF, Sonnemann I, 472 Sorkau E, Steckel J, Steffan-Dewenter I, Stempfhuber B, Tschapka M, Turke M, Venter P, Weiner 473 CN, Weisser WW, Werner M, Westphal C, Wilcke W, Wolters V, Wubet T, Wurst S, Fischer M 474 and Allan E, 2016. Locally rare species influence grassland ecosystem multifunctionality. 
475

476

477

478

479

480

481

482

483

484

485

486

487 488

Philosophical Transactions of the Royal Society B-Biological Sciences 371: 20150269. DOI $0.1098 /$ rstb.2015.0269.

Spiering MJ, Lane GA, Christensen MJ and Schmid J, 2005. Distribution of the fungal endophyte Neotyphodium lolii is not a major determinant of the distribution of fungal alkaloids in Lolium perenne plants. Phytochemistry 66: 195-202.

Stone JK, Polishook JD and White JF, 2004. Endophytic Fungi. In: Foster M, Bills GF, Mueller G (Eds.), Biodiversity of Fungi. Academic Press, Burlington, San Diego, USA, London, UK: Elsevier, p. 777.

Suryanarayanan TS, 2013. Endophyte research: Going beyond isolation and metabolite documentation. Fungal Ecology 6: 561-568.

Tanaka A, Takemoto D, Chujo T and Scott B, 2012. Fungal endophytes of grasses. Current Opinion in Plant Biology 15: 462-468.

The R Development Team, 2014. R: A language and environment for statistical computing. Vienna, Austria: R Foundation for Statistical Computing. http://CRAN.R-project.org.

Thomas MR and Shattock RC, 1986. Filamentous fungal associations in the phylloplane of Lolium perenne. Transactions of the British Mycological Society 87: 255-268.

Valyi K, Rillig MC and Hempel S, 2015. Land-use intensity and host plant identity interactively shape communities of arbuscular mycorrhizal fungi in roots of grassland plants. New Phytologist 205: $1577-1586$.

van der Heijden MGA, Klironomos JN, Ursic M, Moutoglis P, Streitwolf-Engel R, Boller T, Wiemken A and Sanders IR, 1998. Mycorrhizal fungal diversity determines plant biodiversity, ecosystem variability and productivity. Nature 396: 69-72. 
497 Vandegrift R, Roy BA, Pfeifer-Meister L, Johnson BR and Bridgham SD, 2015. The herbaceous

498 landlord: Integrating the effects of symbiont consortia within a single host. PeerJ, 3:e1379, DOI $499 \quad 10.7717 /$ peerj.1379.

500 Vignale MV, Astiz-Gasso MM, Novas MV and Iannone LJ, 2013. Epichloid endophytes confer 501 resistance to the smut Ustilago bullata in the wild grass Bromus auleticus (Trin.). Biological 502 Control 67: 1-7.

503 White IR and Backhouse D, 2007. Comparison of fungal endophyte communities in the invasive 504 panicoid grass Hyparrhenia hirta and the native grass Bothriochloa macra. Australian Journal of 505 Botany 55: 178-185.

506 Wilberforce EM, Boddy L, Griffiths R and Griffith GW, 2003. Agricultural management affects 507 communities of culturable root-endophytic fungi in temperate grasslands. Soil Biology \& 508 Biochemistry 35: 1143-1154.

509 Wirsel SGR, Leibinger W, Ernst M and Mendgen K, 2001. Genetic diversity of fungi commonly 510 associated with common reed. New Phytologist 149: 589-598.

511 Xia C, Zhang X, Christensen MJ, Nan Z and Li C, 2015. Epichloë endophyte affects the ability of 512 powdery mildew (Blumeria graminis) to colonise drunken horse grass (Achnatherum inebrians). 513 Fungal Ecology 16: 26-33.

514 Yang T, Weisenhorn P, Gilbert JA, Ni Y, Sun R, Shi Y and Chu H, 2016. Carbon constrains fungal 515 endophyte assemblages along the timberline. Environmental Microbiology 18: 2455-2469.

516 Yue Q, Miller CJ, White JF and Richardson MD, 2000. Isolation and characterization of fungal 517 inhibitors from Epichloë festucae. Journal of Agricultural and Food Chemistry 48: 4687-4692. 
518 Zabalgogeazcoa I, Gundel PE, Helander M and Saikkonen K, 2013. Non-systemic fungal

519 endophytes in Festuca rubra plants infected by Epichloë festucae in subarctic habitats. Fungal

520 Diversity 60: $25-32$. 


\section{Table $\mathbf{1}$ (on next page)}

Fungal taxa identified in $128 \mathrm{~L}$. perenne leaves from 52 grasslands in three German study regions by Next Generation Sequencing of the ITS rRNA gene region.

Shown are the number of OTUs of each order, as well as their percent relative abundance and their proportions of the sequencing reads. 


\begin{tabular}{|c|c|c|c|c|c|}
\hline Phylum & Class & Order & OTUs & $\%$ of OTUs & $\%$ of reads \\
\hline \multirow[t]{29}{*}{ Ascomycota } & & & 145 & 58.7 & 42.8 \\
\hline & Dothideomycetes & & 60 & 24.3 & 26.1 \\
\hline & & Capnodiales & 13 & 5.3 & 14.8 \\
\hline & & Dothideales & 1 & 0.4 & 0.1 \\
\hline & & Incertae sedis & 5 & 2.0 & 0.3 \\
\hline & & Pleosporales & 36 & 14.6 & 10.3 \\
\hline & & unidentified & 5 & 2.0 & 0.6 \\
\hline & Eurotiomycetes & & 9 & 3.6 & 0.2 \\
\hline & & Chaetothyriales & 6 & 2.4 & 0.1 \\
\hline & & Eurotiales & 3 & 1.2 & 0.1 \\
\hline & Lecanoromycetes & & 2 & 0.8 & 0.0 \\
\hline & & Lecanorales & 2 & 0.8 & 0.0 \\
\hline & Leotiomycetes & & 24 & 9.7 & 7.6 \\
\hline & & Erysiphales & 3 & 1.2 & 0.1 \\
\hline & & Helotiales & 21 & 8.5 & 7.6 \\
\hline & Pezizomycetes & & 1 & 0.4 & 0.1 \\
\hline & & Pezizales & 1 & 0.4 & 0.1 \\
\hline & Pezizomycotina & & 4 & 1.6 & 1.1 \\
\hline & & Incertae sedis & 4 & 1.6 & 1.1 \\
\hline & Saccharomycetes & & 2 & 0.8 & 0.0 \\
\hline & & Saccharomycetales & 2 & 0.8 & 0.0 \\
\hline & Sordariomycetes & & 27 & 10.9 & 5.2 \\
\hline & & Hypocreales & 13 & 5.3 & 2.2 \\
\hline & & Sordariales & 4 & 1.6 & 0.2 \\
\hline & & Incertae sedis & 1 & 0.4 & 0.2 \\
\hline & & Xylariales & 9 & 3.6 & 2.6 \\
\hline & Taphrinomycetes & & 2 & 0.8 & 0.1 \\
\hline & & Taphrinales & 2 & 0.8 & 0.1 \\
\hline & unidentified & & 14 & 5.7 & 2.4 \\
\hline \multirow[t]{9}{*}{ Basidiomycota } & & & 82 & 33.2 & 53.9 \\
\hline & Agaricomycetes & & 7 & 2.8 & 0.2 \\
\hline & & Agaricales & 5 & 2.0 & 0.1 \\
\hline & & Polyporales & 1 & 0.4 & 0.0 \\
\hline & & Trechisporales & 1 & 0.4 & 0.0 \\
\hline & Agaricostilbomycetes & & 5 & 2.0 & 0.2 \\
\hline & & Agaricostilbales & 5 & 2.0 & 0.2 \\
\hline & Cystobasidiomycetes & & 3 & 1.2 & 0.3 \\
\hline & & Incertae sedis & 2 & 0.8 & 0.1 \\
\hline
\end{tabular}




\begin{tabular}{|c|c|c|c|c|c|}
\hline & & unidentified & 1 & 0.4 & 0.2 \\
\hline & Exobasidiomycetes & & 3 & 1.2 & 0.1 \\
\hline & & Entylomatales & 1 & 0.4 & 0.0 \\
\hline & & unidentified & 2 & 0.8 & 0.1 \\
\hline & Microbotryomycetes & & 19 & 7.7 & 6.4 \\
\hline & & Leucosporidiales & 9 & 3.6 & 1.9 \\
\hline & & Microbotryales & 2 & 0.8 & 0.2 \\
\hline & & Incertae sedis & 1 & 0.4 & 0.0 \\
\hline & & Sporidiobolales & 7 & 2.8 & 4.2 \\
\hline & Pucciniomycetes & & 1 & 0.4 & 0.0 \\
\hline & & Pucciniales & 1 & 0.4 & 0.0 \\
\hline & Tremellomycetes & & 38 & 15.4 & 43.5 \\
\hline & & Cystofilobasidiales & 6 & 2.4 & 2.9 \\
\hline & & Filobasidiales & 6 & 2.4 & 4.4 \\
\hline & & Tremellales & 24 & 9.7 & 34.9 \\
\hline & & unidentified & 2 & 0.8 & 1.2 \\
\hline & Ustilaginomycotina & & 3 & 1.2 & 0.1 \\
\hline & & Malasseziales & 3 & 1.2 & 0.1 \\
\hline & Wallemiomycetes & & 1 & 0.4 & 0.1 \\
\hline & & Wallemiales & 1 & 0.4 & 0.1 \\
\hline & unidentified & & 2 & 0.8 & 3.1 \\
\hline Chytridiomycota & & & 1 & 0.4 & 0.1 \\
\hline & Chytridiomycetes & & 1 & 0.4 & 0.1 \\
\hline & & Rhizophlyctidales & 1 & 0.4 & 0.1 \\
\hline unidentified & & & 19 & 7.7 & 3.3 \\
\hline
\end{tabular}




\section{Table 2 (on next page)}

Dominant fungal genera identified in $128 \mathrm{~L}$. perenne leaves from 52 grasslands in three German study regions by Next Generation Sequencing of the ITS rRNA gene region.

Shown is the proportion of sequencing reads for each genus. Table includes only genera which account for a minimum of $1 \%$ of the sequencing reads and does not include undefined OTUs. 


\begin{tabular}{llllll}
\hline Phylum & Class & Order & Family & Genus & $\%$ of reads \\
\hline Basidiomycota & Tremellomycetes & Tremellales & Incertae sedis & Cryptococcus & 24.9 \\
Ascomycota & Dothideomycetes & Capnodiales & Mycosphaerellaceae & Mycosphaerella & 11.1 \\
Basidiomycota & Tremellomycetes & Tremellales & Incertae sedis & Bullera & 4.9 \\
Basidiomycota & Tremellomycetes & Filobasidiales & Filobasidiaceae & Filobasidium & 4.4 \\
Basidiomycota & Tremellomycetes & Tremellales & Incertae sedis & Dioszegia & 4.2 \\
Ascomycota & Dothideomycetes & Pleosporales & Didymellaceae & Neoascochyta & 4.1 \\
Basidiomycota & Microbotryomycetes & Sporidiobolales & Incertae sedis & Sporobolomyces & 4.1 \\
Ascomycota & Leotiomycetes & Helotiales & Incertae sedis & Helgardia & 3.1 \\
Ascomycota & Leotiomycetes & Helotiales & Helotiaceae & Articulospora & 2.6 \\
Ascomycota & Sordariomycetes & Xylariales & Incertae sedis & Monographella & 2.4 \\
Basidiomycota & Tremellomycetes & Cystofilobasidiales & Cystofilobasidiaceae & Itersonilia & 1.1 \\
Basidiomycota & Microbotryomycetes & Leucosporidiales & Leucosporidiaceae & Leucosporidium & 1.1 \\
Ascomycota & Dothideomycetes & Pleosporales & Incertae sedis & Boeremia & 1.0 \\
Ascomycota & Pezizomycotina_cls_Incertae_sedis & Incertae_sedis & Incertae sedis & Volucrispora & 1.0 \\
Basidiomycota & Tremellomycetes & Cystofilobasidiales & Incertae sedis & Mrakiella & 1.0 \\
\hline
\end{tabular}




\section{Table 3(on next page)}

\section{Statistical Results.}

Effects of Epichloë infection (INF), season (SEA), region (REG) and land-use intensity (LUI) on fungal species richness (number of OTUs), evenness, Shannon diversity and fungal composition. Significant $p$-values are highlighted in bold. 


\begin{tabular}{|c|c|c|c|c|c|c|c|c|c|c|}
\hline & \multirow[b]{2}{*}{ df } & \multicolumn{2}{|c|}{$\begin{array}{l}\text { Species } \\
\text { richness }[r]^{1}\end{array}$} & \multicolumn{2}{|c|}{$\begin{array}{l}\text { Species } \\
\text { evenness }\left[J^{\prime}\right]^{1}\end{array}$} & \multicolumn{2}{|c|}{$\begin{array}{l}\text { Shannon } \\
\text { diversity }\left[H^{\prime}\right]^{1}\end{array}$} & \multicolumn{3}{|c|}{$\begin{array}{l}\text { Fungal } \\
\text { composition }^{2}\end{array}$} \\
\hline & & $F$ & $p$ & $F$ & $p$ & $F$ & $p$ & $d f$ & $F$ & $p$ \\
\hline INF & 1,74 & 1.91 & 0.171 & 1.15 & 0.287 & 0.49 & 0.485 & 1,122 & 0.64 & 0.788 \\
\hline SEA & 1,74 & 47.41 & $<0.001$ & 20.14 & $<0.001$ & 6.01 & 0.017 & 1,122 & 11.45 & $<0.001$ \\
\hline REG & 2,48 & 7.63 & 0.001 & 11.99 & $<0.001$ & 0.43 & 0.655 & 2,122 & 9.08 & $<0.001$ \\
\hline LUI & 1,48 & 2.03 & 0.161 & 0.37 & 0.545 & 2.00 & 0.164 & 1,122 & 1.51 & 0.129 \\
\hline
\end{tabular}

${ }^{1}$ Data were analysed by a linear mixed-effect model with study site ID as random effect

${ }^{2}$ Data were analysed with PERMANOVA (9999 permutations) 


\section{Figure 1 (on next page)}

Material from the same grass tiller of each sampled $L$. perenne plant was used for immunoblot assays and NGS.

(a) Parts of the basal stem and leaf sheaths were used for detection of Epichloë endophyte by immunoblot assays, while (b) parts of the basal leaf blades were used for analyses of the foliar fungal assemblages by NGS. 
PeerJ

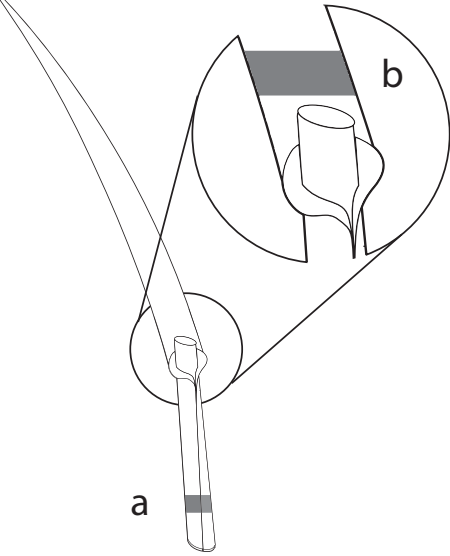




\section{Figure 2 (on next page)}

Species accumulation curves.

Species accumulation curves of fungal OTUs found in lower leaf blades of $L$. perenne indicate species saturations (a) for each study region: $\mathrm{ALB}, \mathrm{HAl}$, and $\mathrm{SCH}$; and (b) for both seasons: spring, summer. All fungal OTUs were included, resulting in asymptotic curves. 


\section{(a) Region}

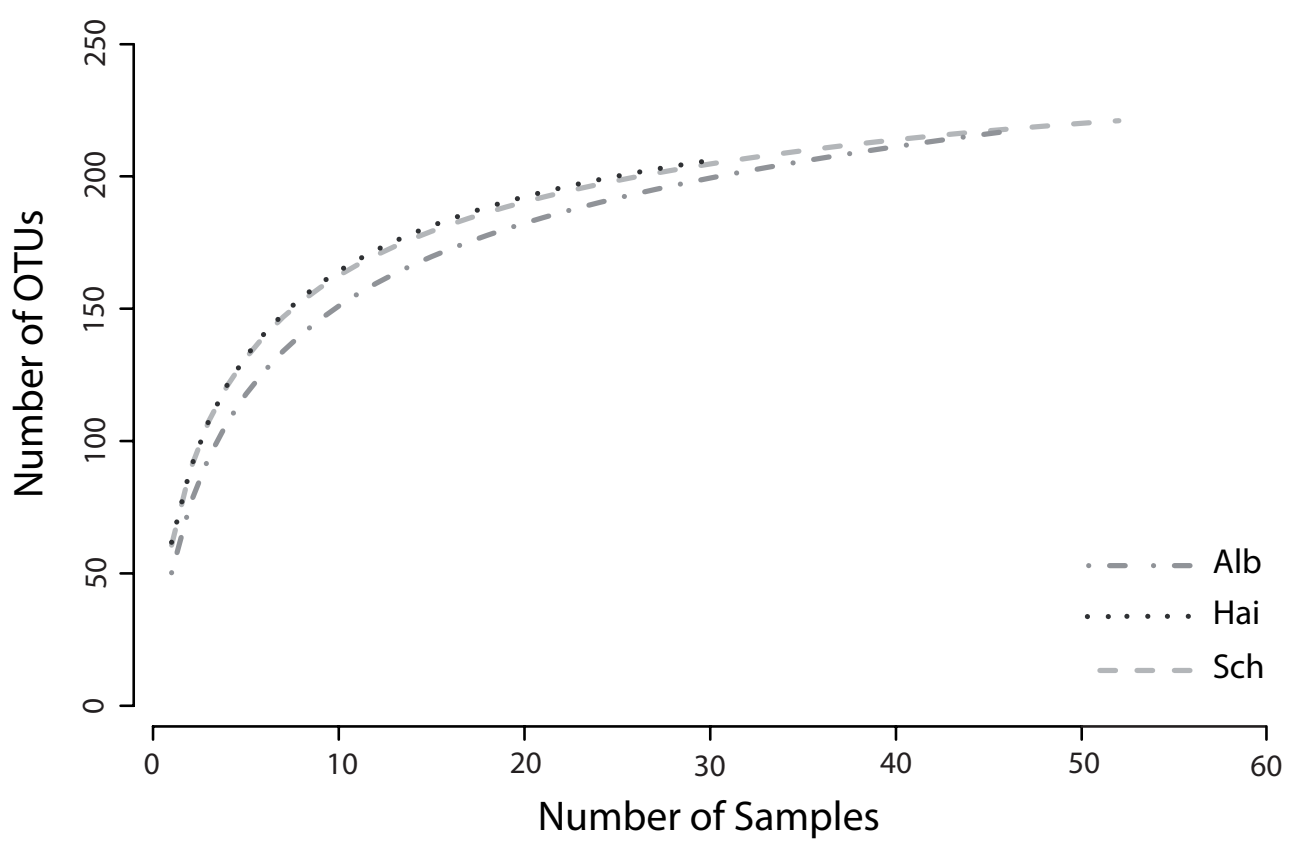

(b) ${ }^{\text {crit to be rewew }}$ Sen

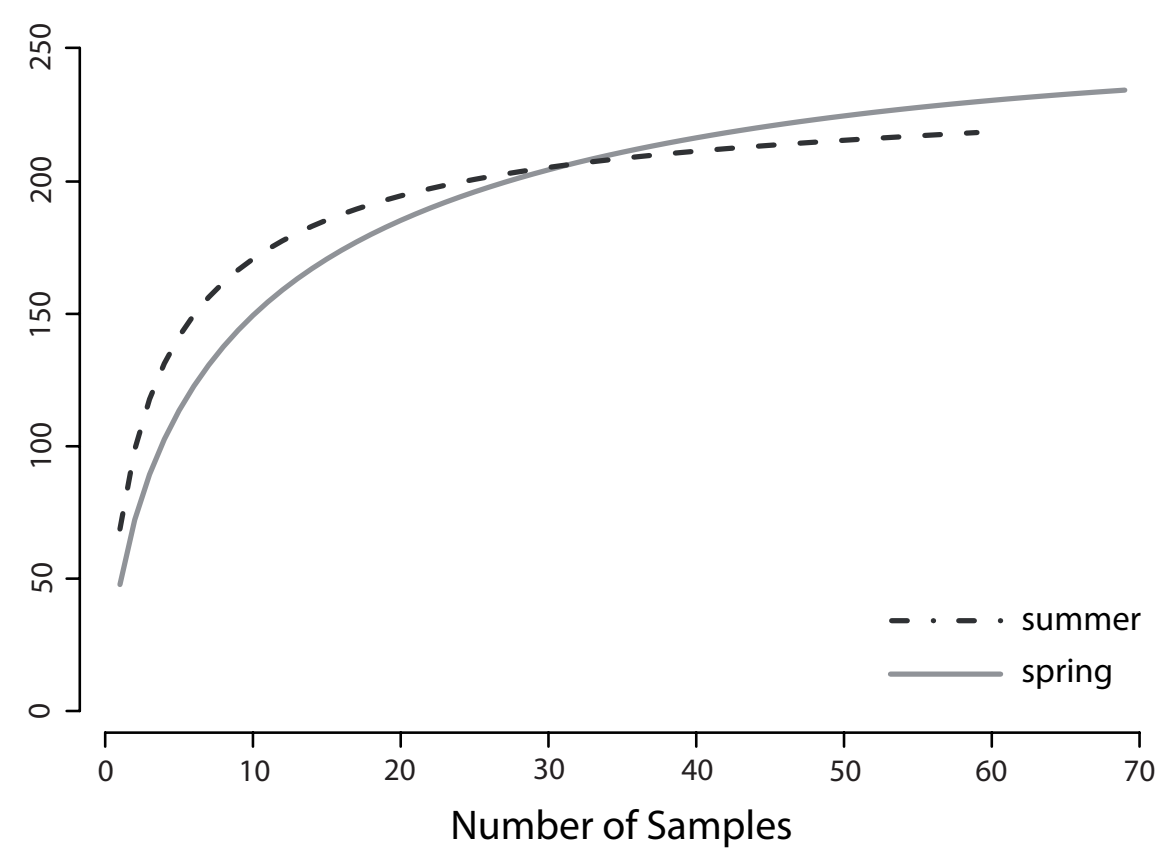




\section{Figure 3 (on next page)}

Effects on the species indices of the foliar fungal assemblages in the grass $L$. perenne.

The (a) species richness (number of OTUs), (b) evenness and (c) diversity of the foliar fungal assemblages in the grass $L$. perenne depending on season (left) and study region (right). Means \pm SE are shown. Different letters above bars indicate significantly different groups at $p<0.05$, corrected for multiple comparisons. 
(a)

\section{Season}

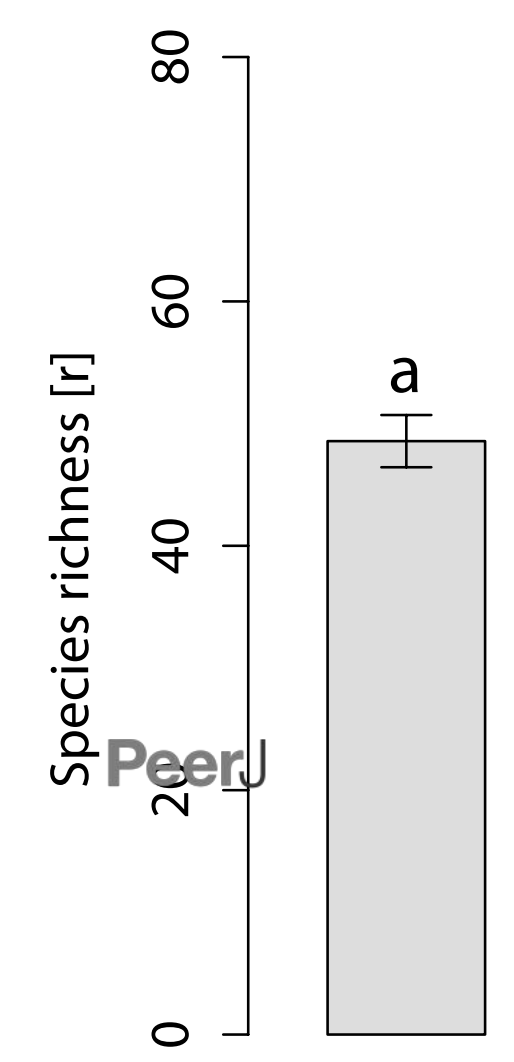

$p<0.001$

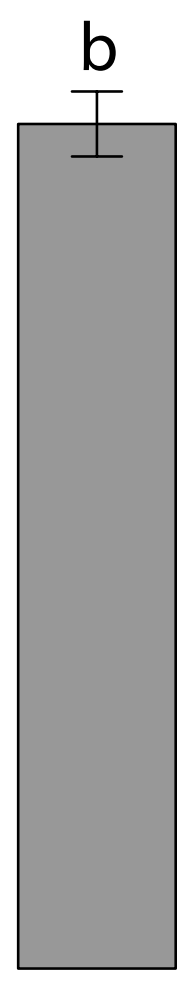

(b)

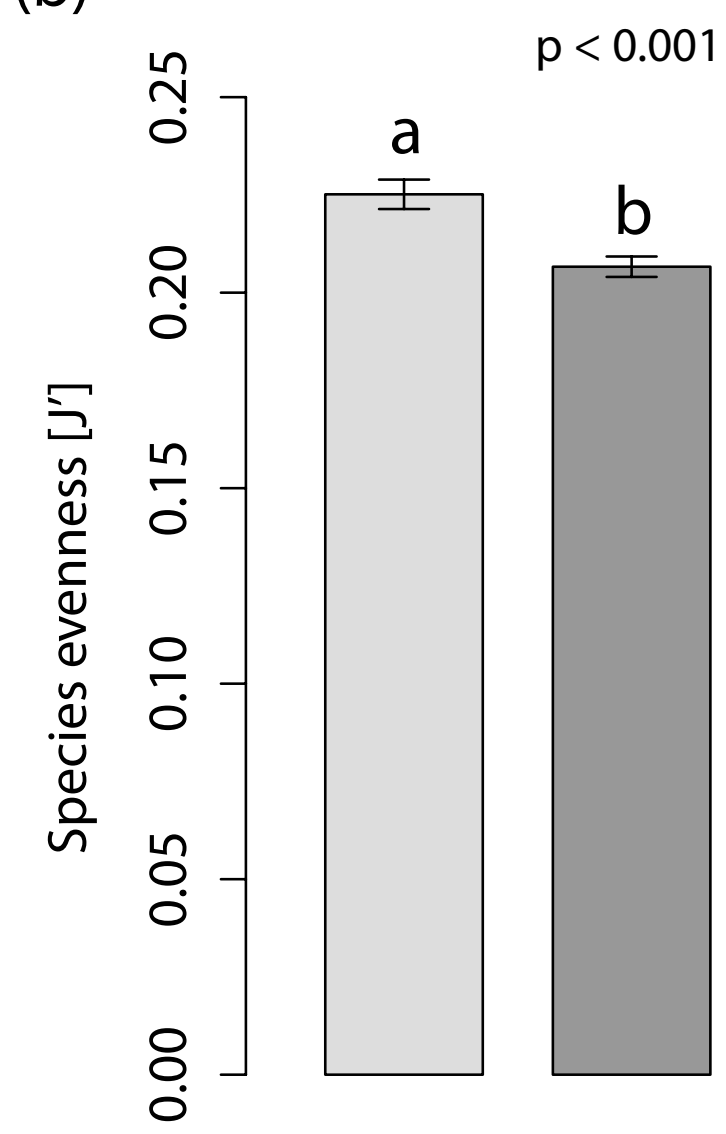

(c)

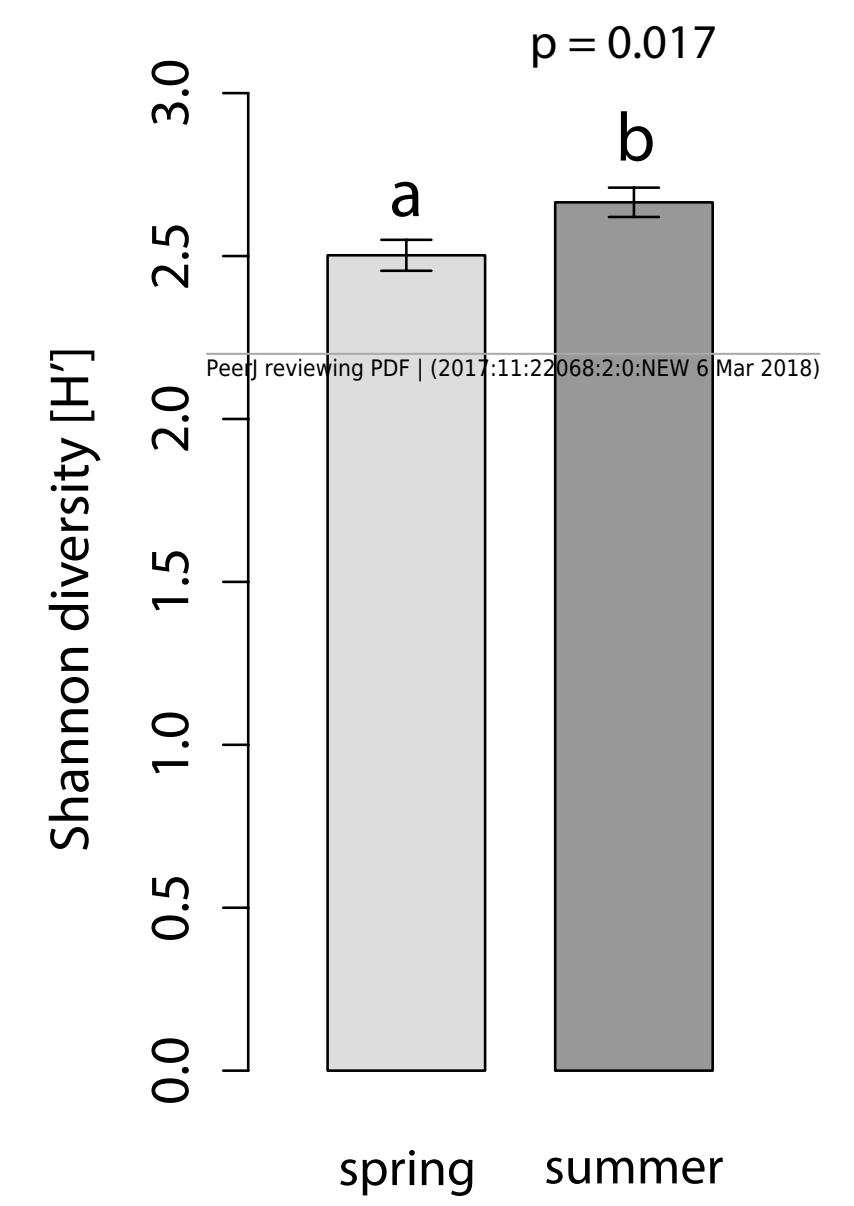

\section{Region}

$p=0.001$

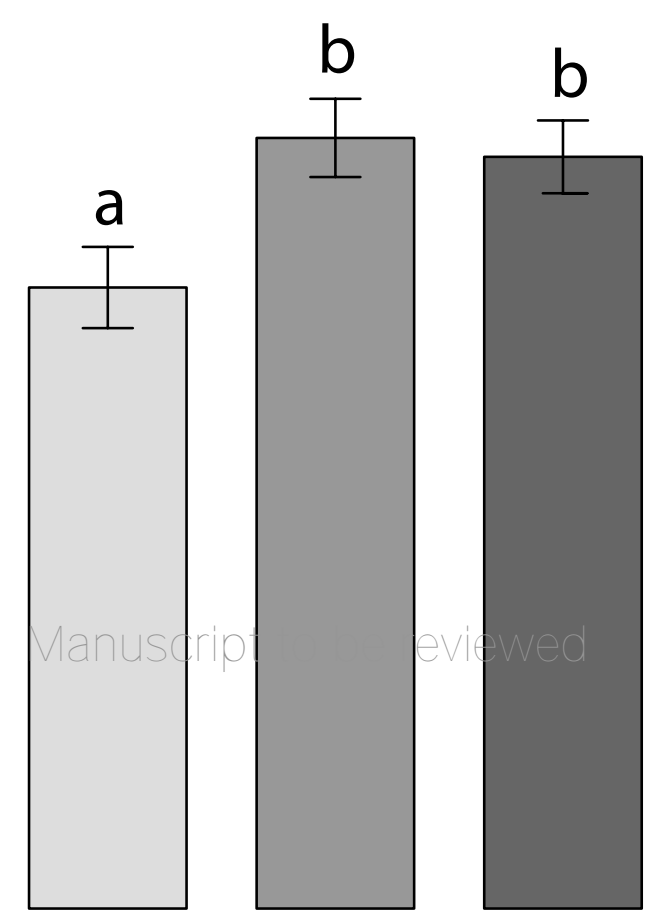

$p<0.001$
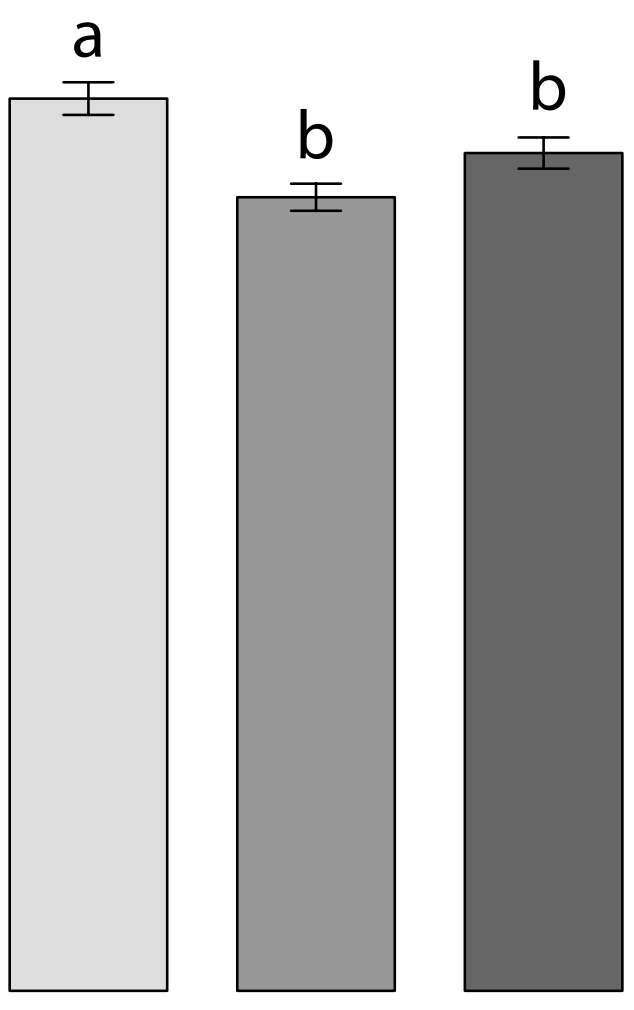

n.s.

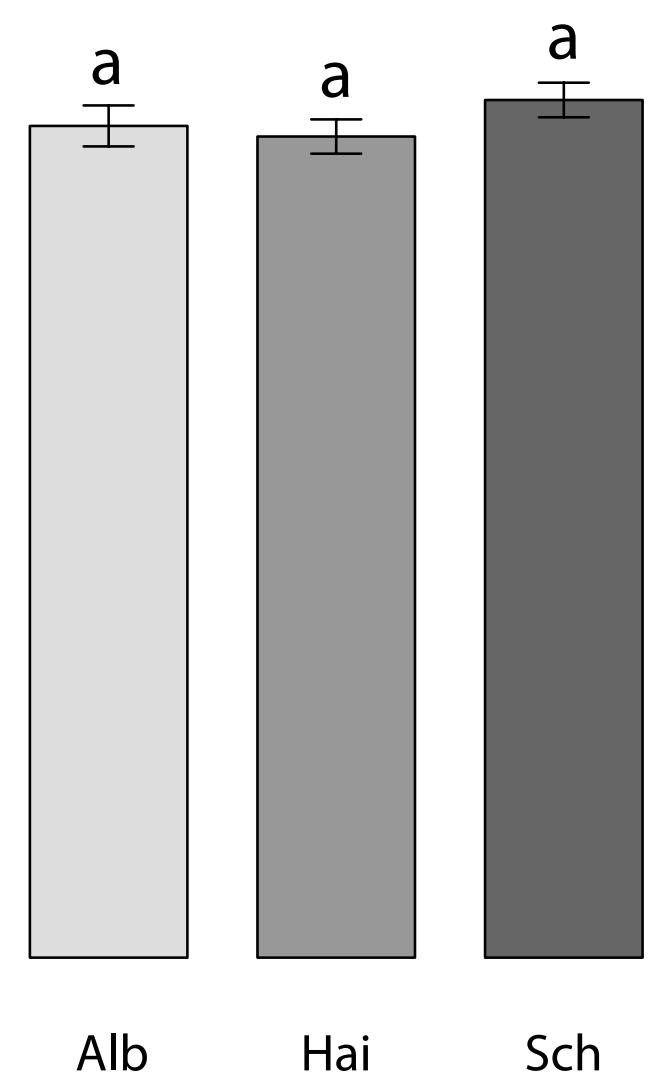


Figure 4(on next page)

NMDS ordination (stress $=0.20$ ) of foliar fungal community composition in L. perenne.

Relationships with (a) study region, (b) season, (c) land-use intensity and (d) the presence of Epichloë infection are highlighted. Dots represent different foliar fungal assemblages of $L$. perenne. Polygons indicate clustering of fungal compositions based on the analysed variables. 
